Original research article

\title{
Lectin-based analysis of human milk immunoglobulin G fucosylated variants in relation to milk maturation and perinatal risk factors
}

\author{
Jolanta Lis-Kuberka ${ }^{\mathrm{a}}$, Magdalena Orczyk-Pawiłowicz ${ }^{\mathrm{a}, *}$, Barbara Królak-Olejnik ${ }^{\mathrm{b}}$, \\ Marta Berghausen-Mazur ${ }^{\mathrm{c}}$, Karolina Barańska ${ }^{\mathrm{b}}$, Iwona Kątnik-Prastowska ${ }^{\mathrm{a}}$ \\ ${ }^{a}$ Wroclaw Medical University, Department of Chemistry and Immunochemistry, Wrocław, Poland \\ ${ }^{\mathrm{b}}$ Wroclaw Medical University, Department and Clinic of Neonatology, Wrocław, Poland \\ ${ }^{\mathrm{c}}$ Wroclaw Medical University, 1st Department and Clinic of Gynaecology and Obstetrics, Wrocław, Poland
}

\section{A R T I C L E I N F O}

\section{Article history:}

Received 18 May 2017

Received in revised form 19 December 2017

Accepted 1 February 2018

Available online 13 February 2018

\section{Keywords:}

Fucosylation

Human lactation

Human milk

Immunoglobulin G

Lectins

\begin{abstract}
A B S T R A C T
Background: Fucosylated glycotopes of milk immunoglobulin G ( $\operatorname{IgG}$ ) are ligands in reactions of biological recognition protecting newborns against infection and ensuring proper development.

Materials and methods: Relative amounts of IgG fucosyl-glycovariants in milk of mothers giving birth to term and premature newborns (term and preterm milk groups) were analysed by lectin-IgG-ELISA using $\alpha 1,2-, \alpha 1,3-$, and $\alpha 1,6$-fucose specific biotinylated Ulex europaeus (UEA), Tetragonolobus purpureus (LTA), and Lens culinaris (LCA) lectins, respectively.

Results: The term and preterm milk IgG glycovariants were highly reactive with UEA, LTA, and LCA, whereas maternal plasma IgG poorly or at all. During milk maturation the IgG of very preterm and preterm milk compared to term milk differed by lower relative amounts of UEA-, higher of LTA-, and nearly stable expression of LCA-reactive glycotopes. Moreover, lower $\alpha 1,2$ - and higher $\alpha 1,3-$ relative amounts of lectin-dependent milk IgG-fucosylated glycovariants were found to be associated with an infectious disease of lactating mothers.

Conclusion: The highly fucosylated glycovariants of human IgG given with mothers' milk to immunologically immature newborn seem to be bifunctional molecules with potential therapeutic properties. The analysis of fucosylation status of milk IgG by simple lectin-IgG-ELISA may be helpful to control the immunological quality of milk for milk banking.

(c) 2018 Faculty of Health and Social Sciences, University of South Bohemia in Ceske Budejovice. Published by Elsevier Sp. z o.o. All rights reserved.
\end{abstract}

\section{Introduction}

Among many human milk components supporting adequate growth and development of newborns during the first months of life (AAP, 2012; WHO, 2016a,b) the maternal immunoglobulins delivered to the babies are involved in naturally compensatory mechanisms of the unfavourable effects of neonatal immunodeficiency (Chirico et al., 2008). Immunoglobulin G (IgG) concentration in human milk is ranging from 20 to $117 \mathrm{mg} / \mathrm{l}$ (Arnold et al., 2005; Broadhurst et al., 2015; Koenig et al., 2005) and is approximately 130-250 times lower than in human serum

Abbreviations: HMOs, human milk oligosaccharides; IgG, immunoglobulin G; LCA, Lens culinaris lectin; LTA, Tetragonolobus purpureus lectin; UEA, Ulex europaeus lectin; Fuc, fucose.

* Author for correspondence: Wroclaw Medical University, Department of Chemistry and Immunochemistry, Bujwida 44a, 50-345 Wrocław, Poland.

E-mail address: magdalena.orczyk-pawilowicz@umed.wroc.pl

(M. Orczyk-Pawiłowicz).
(5-15 g/l) (Arnold et al., 2005). Zhang et al. (2013) observed an increase of the relative abundance of IgG from week 1 to 12 months in ten milk samples from healthy mother. On the other hand, França et al. $(2010,2012)$ and Broadhurst et al. (2015) reported that the concentration of IgG did not differ significantly between the groups within any period of lactation, but pointed out the inherent physiological differences between mothers.

Several studies have demonstrated that human plasma IgG has three potential glycosylation sites situated in crystallisable fragment $(\mathrm{Fc})$, antigen-binding fragment (Fab), and hinge region (Arnold et al., 2007; Bondt et al., 2014; Plomp et al., 2015). All IgG sub-isotypes contain a single N-linked glycan at Asn-297 of the C $\gamma 2$ domain of Fc fragment. It is a complex-type biantennary glycan, whose pentasaccharide core is elongated by galactose and can be expanded by the addition of core fucose, and rarely by sialic acid (Arnold et al., 2007; Bondt et al., 2014; Shade and Anthony, 2013; Vidarsson et al., 2014). The most abundant N-glycan of FC region of IgG has a high level of core fucose ( $94 \%)$ and low level of sialic acid ( 10\%) and bisecting GlcNAc ( 10\%) (Bondt et al., 2014). 
Moreover, about $15-25 \%$ of plasma IgG contains a complex-type biantennary N-glycan at antigen-binding fragment (Fab) which is fucosylated ( $69 \%)$, sialylated $(\sim 72 \%)$ and may contain bisecting GlcNAc ( 45\%) (Bondt et al., 2014; Vidarsson et al., 2014; Zauner et al., 2013). The third glycosylation place can be located in hinge region of human sera $\operatorname{IgG}_{3}$, and may contain three mono- or disialylated O-linked glycans (Plomp et al., 2015).

To date there are more than twenty IgG glycoforms (syn. glycovariants) described, whose mutual distribution is tissuedependent and might be modified during growth and some diseases (Arnold et al., 2007; Gornik et al., 2012; OrczykPawiłowicz et al., 2012). The exposed residues of sialic acid and fucose on $\operatorname{IgG}$ are reported to take part in variety of biological functions, such as immunoregulation, inflammation progression, complement activation, opsonizing, mediation of antibody-dependent cellular cytotoxicity (ADCC) and can serve as ligand for bacterial adhesins (Bondt et al., 2014; Gornik et al., 2012; Thieker et al., 2016; Vidarsson et al., 2014; Zauner et al., 2013). Alterations of IgG glycosylation affect affinity binding of antigen and Fc $\gamma R$, antibody-mediated effector functions, release of pro-inflammatory factors (Arnold et al., 2007; Nimmerjahn and Ravetch, 2007), ADCC and antitumor activity as well as anti- and pro-inflammatory properties of IgG (Gornik et al., 2012; Kaneko et al., 2006; Shade and Anthony, 2013; Zauner et al., 2013). The core fucosylation $\alpha 1,6$ of IgG is known to have an influence on Fc region conformation. In consequence, a lack of a core fucose on IgG significantly decreases the ability of IgG to bind to Fc $\gamma$ RIIIa receptor on natural killer cells and macrophages. As suggested by Gornik et al. (2012) it leads to "safety switch" and in that way prevents elicitation of potentially destructive ADCC.

Fucosylated glycotopes are well known ligands in biological recognition. Alpha 1,2- and $\alpha 1,3$-linked fucoses are structural elements of the Lewis antigens, such as Lewis ${ }^{y}$, Lewis $^{x}$, sialo-Lewis ${ }^{x}$, expressed on outer arms of $\mathrm{N}$ - and O-glycans. In contrast, $\alpha 1,6$ linked fucose is attached exclusively to the core part of $\mathrm{N}$-glycans. The fucosylated glycotopes of IgG are essential for biological reactions, such as cell adhesion, signalling, cell growth and differentiation. All of the above events are particularly important during early human development and in protection of infants against infection (Becker and Lowe, 2003; Orczyk-Pawiłowicz and Kątnik-Prastowska, 2011). Moreover, IgG may survive in the gastrointestinal tract of newborns and can serve as substitutes of S-IgA (Wilson and Ogra, 2011). This hypothesis is additionally supported by the fact that in bovine model, colostral IgG showed protective effect against enterotoxigenic E. coli (Freedman et al. 1998; Hurley and Theil, 2011).

In light of the significant role of fucosylated glycotopes in the biological recognition processes and since milk is not only food, but also specialized, high-quality medicine for premature newborns, we analysed expression of conformationally accessible fucose residues on human milk IgG, present in a milk sample in their native form, which in vivo might be recognized by endogenous intestinal receptors and/or bacterial lectins. In the study, the concentration of $\operatorname{IgG}$ and the expression of $\alpha 1,6-, \alpha 1,3-$, and $\alpha 1,2$ linked fucosyl residues on milk and plasma IgG of healthy and infected mothers giving birth to term and premature newborns were analysed in relation to lactation stages during human lactation from the $1 \mathrm{st} / 2$ nd day to the 55th/40th day by lectinbased enzyme-linked immunosorbent assay (lectin-IgG-ELISA) using fucose-specific Lens culinaris (LCA), Tetragonolobus purpureus (LTA), and Ulex europaeus (UEA) agglutinins, respectively. LectinIgG-ELISA is a simple, quick and cost-effective method which allows for the simultaneous analysis of large number of samples without glycan separation steps as is required for high-performance liquid chromatography and mass spectrometry techniques.

\section{Materials and methods}

\section{Milk and plasma samples}

The milk samples called "term milk" $(n=186)$ were obtained from healthy lactating women (21-35 years old) who delivered healthy newborn at term (37 1/7-41 6/7 weeks of gestation) at the 1 st Department and Clinic of Gynecology and Obstetrics at Wroclaw Medical University (Wroclaw, Poland). The milk samples called "preterm milk" $(n=106)$ were obtained from mothers (25-38 years old) who delivered preterm newborn (26 1/7-35 6/7 weeks of gestation) and who were treated at the Department and Clinic of Neonatology at Wroclaw Medical University (Wroclaw, Poland). Mothers who used tobacco products, illicit drugs or alcohol were not included in the study. Informed written consent was obtained from all mothers according the protocol approved by

Table 1

Clinical characteristics of the preterm group.

\begin{tabular}{|c|c|c|}
\hline Clinical parameter & Groups & Number of donor milk mothers (number of milk samples, \%) \\
\hline \multirow[t]{5}{*}{ Gestation age } & $\begin{array}{l}\text { Extremely Preterm (EP) } \\
(26.5 \pm 0.7 \text { weeks })\end{array}$ & $2(5,4.7 \%)$ \\
\hline & Very Preterm (VP) & $21(41,38.7 \%)$ \\
\hline & $(30.3 \pm 1.7$ weeks $)$ & \\
\hline & Moderate Preterm (MP) & $17(60,56.6 \%)$ \\
\hline & $(33.8 \pm 0.9$ weeks $)$ & \\
\hline \multirow[t]{4}{*}{ Day of lactation } & $\begin{array}{l}\text { Early colostrum } \\
\text { (1-3 days) }\end{array}$ & $6(5.7 \%)$ \\
\hline & $\begin{array}{l}\text { Colostrum } \\
\text { (4-7 days) }\end{array}$ & $15(14.1 \%)$ \\
\hline & $\begin{array}{l}\text { Transitional milk } \\
\text { (8-14 days) }\end{array}$ & $30(28.3 \%)$ \\
\hline & $\begin{array}{l}\text { Mature milk } \\
\text { (15-45 days) }\end{array}$ & $55(51.9 \%)$ \\
\hline \multirow[t]{2}{*}{ Mode of delivery } & Vaginal & $4(18,17.0 \%)$ \\
\hline & Caesarean section & $36(88,83.0 \%)$ \\
\hline \multirow[t]{3}{*}{ Mother's status } & Maternal infection & $21(50,47.2 \%)$ \\
\hline & PROM & $14(44,41.5 \%)$ \\
\hline & Hypertension & $9(17,16.0 \%)$ \\
\hline \multirow[t]{3}{*}{ Newborn's status } & $\begin{array}{l}\text { Birth weight } \\
\text { (grams, mean } \pm \text { SD) }\end{array}$ & $1577 \pm 420$ \\
\hline & Antibiotic treatment $(n)$ & 33 \\
\hline & Hypertrophy $(n)$ & 7 \\
\hline
\end{tabular}

According to WHO Preterm births (2016): EP, Extremely Preterm; VP, Very Preterm; MP, Moderately Preterm; PROM, Premature Rupture of Membranes. 
Ethics Committee at Wroclaw Medical University (KB-30/2013 and KB-411/2015).

The term milk group consisted of mothers $(n=186)$, without signs of infection, giving birth to term single healthy newborns weight from 2650 to $3900 \mathrm{~g}(3360 \pm 349 \mathrm{~g})$, without genetic disorders. $83 \%$ of term milk samples were from mothers with secretor status. $52 \%$ of newborns in the "term" group were born by caesarean section.

The preterm milk group comprised of mothers $(n=40)$ with single pregnancy (Table 1) who delivered newborns assigned (WHO Preterm births, 2016) to the groups Extremely Preterm (EP: $<28$ 0/7 weeks of gestation, $n=5$ ), Very Preterm (VP: $281 / 7-32$ 0/7 weeks of gestation, $n=41$ ), and Moderate Preterm (MP: 32 1/7-36 $0 / 7$ weeks of gestation, $n=60$ ) and $73 \%$ of them had secretor status. Among mothers giving birth to premature newborns 21 mothers suffered from infections, 14 had a premature rupture of membranes before parturition, and 9 had hypertension during pregnancy.

To obtain plasma samples, blood samples from 40 lactating women on the 2 nd postpartum day $(n=40)$ were taken with $3.2 \%$ sodium citrate.

\section{Sample collection and preparation}

The samples of human milk of term and preterm groups (from 1 st to 55th and from 2 nd to 40th days of lactation, respectively) were collected by a lactation consultant from the breast by manual expression and/or a breast pump at the end of nursing (hindmilk) by complete breast emptying, once per day, at the same time (8:00-10:00 a.m.). There was significant interindividual variation in volume of hindmilk, from $1 \mathrm{ml}$ for early colostrum to $100 \mathrm{ml}$ for mature milk. All milk samples were frozen and stored immediately at $-20^{\circ} \mathrm{C}$ until analysis. Skim milk (aqueous phase) was prepared by centrifugation at $3500 \mathrm{~g}$ at $4{ }^{\circ} \mathrm{C}$ for $35 \mathrm{~min}$, after which the fat layer and cells were removed. The aliquots of skim milk and plasma samples were stored at $-20^{\circ} \mathrm{C}$ until analysis.

The milk samples were divided into: (1) early colostrum (postpartum days $1-3 ; n=40$ for term and $n=6$ for preterm milk), (2) colostrum (postpartum days $4-7 ; n=75$ for term and $n=15$ for preterm milk), (3) transitional milk (postpartum days $8-14 ; n=43$ for term and $n=30$ for preterm milk), (4) mature milk (postpartum days $15-55 ; n=28$ for term and $n=55$ for preterm milk).

Additionally, the preterm milk samples were divided into: samples from mothers suffering an infectious disease $(n=50)$ and samples from mothers without infection $(n=56)$. Maternal urinary and upper respiratory tract infections were defined based on a positive microbiological culture and CRP higher than $100 \mathrm{mg} / \mathrm{l}$.

\section{$\operatorname{IgG}$ concentration}

IgG concentration was determined by "sandwich type" ELISA using: 1) $\mathrm{F}\left(\mathrm{ab}^{\prime}\right)_{2}$ fragment of goat anti-human IgG (Jackson ImmunoResearch, USA) as a capture antibody, which extracted specifically IgG from a sample, 2) phosphatase-labelled rabbit antihuman IgG Fcy fragment specific antibodies (Jackson ImmunoResearch, USA). For testing $100 \mu \mathrm{l}$ of 1000-, 2500- and 5000- fold diluted milk, 400000- and 800000- fold diluted plasma, and IgG standard preparation from 0.2 to $12.5 \mathrm{ng} / 100 \mu \mathrm{l}$ (Jackson ImmunoResearch, USA) were taken. The test was assayed with 4-nitrophenyl phosphate (SERVA, Heidelberg, Germany) as the enzyme substrate and absorbance was measured in a Stat Fax 2100 Microplate Reader (Awareness Technology Inc., Palm City, FL, USA) at $405 \mathrm{~nm}$ with $630 \mathrm{~nm}$ as the reference filter. All ELISA immunobinding and washing steps were carried out in TRIS-buffered saline (TBS, $\mathrm{pH}$ 7.5) containing $0.2 \%$ Tween 20.

\section{Lectin-reactive fucosylvariants of $\operatorname{Ig} G$}

Fucose expression on IgG was determined by a slightly modified lectin-IgG-ELISA (Orczyk-Pawiłowicz et al., 2012) using specific biotinylated lectins (Vector Laboratories Inc., Burlingame, USA): Lens culinaris lectin (LCA), Tetragonolobus purpureus lectin (LTA), and Ulex europaeus lectin (UEA) showing binding preferences to fucose (Table 2) (Wu et al., 2009) linked by glycosidic linkages $\alpha 1,6-, \alpha 1,3-$, and $\alpha 1,2-$, respectively. However, the specificity of used lectins is not absolute and can be broader then just to fucose. $\mathrm{F}\left(\mathrm{ab} \mathrm{b}^{\prime}\right)_{2}$ fragment of goat anti-human IgG (Jackson ImmunoResearch, USA) diluted $1: 1000$ in $10 \mathrm{mM}$ TBS, pH 8.5 showing a lack of reactivity with increasing concentrations of fucose-specific lectins in preliminary experiments, was used to coat a polystyrene microtitre ELISA plate, extract and specifically bind IgG from a sample. In preliminary experiments the amount of IgG as well as a concentration of lectins used in Lectin-IgG-ELISA fulfilling the conditions of proportionality have been selected. For the test, $100 \mu \mathrm{l}$ of milk and plasma samples were taken which were prediluted in $10 \mathrm{mM}$ TBS pH 7.5, $10 \mathrm{mM} \mathrm{CaCl}_{2}, 10 \mathrm{mM} \mathrm{MgCl}_{2}$, $0.05 \%$ Tween 20 and $0.5 \%$ glycerin, to a $\operatorname{IgG}$ concentration of $2 \mathrm{mg} / \mathrm{l}$ (200 ng per well). The presence of the respective fucosyl residues on IgG was detected by the reaction with the specific biotinylated lectins LCA (1:5000), LTA (1:5000), and UEA (1:500), respectively. The relative amount of formed IgG-lectin complex was determined with phosphatase-labelled ExtrAvidin (1:20000) (Sigma, St. Louis, MO, USA), and then detected by the reaction with 4-nitrophenyl phosphate. The absorbance (AU) was measured in a Stat Fax 2100 Microplate Reader. The absorbance values were found to be proportional to the increasing amount of fucose residue on IgG reactive with specific lectin.

All samples were analysed in duplicate. Controls were performed to demonstrate the specificity of the lectins as well as the absence of detectable endogenous reactive materials. The positive control for LCA, LTA, and UEA was a native haptoglobin and an asialo-haptoglobin preparation derived from ovarian cancer fluid (Kątnik et al., 1994). The negative control was an albumin preparation included in the test instead of milk and plasma samples. The background absorbances (TBS included instead of lectin, ExtrAvidin-AP, and samples, respectively) ranged from 0.04

Table 2

Major binding specificities of used lectins.

\begin{tabular}{|c|c|c|c|}
\hline Origin and used abbreviation of lectin & $\begin{array}{l}\text { Lens culinaris } \\
\text { (LCA) }\end{array}$ & $\begin{array}{l}\text { Tetragonolobus purpureus } \\
\text { (LTA) }\end{array}$ & $\begin{array}{l}\text { Ulex europaeus } \\
\text { (UEA) }\end{array}$ \\
\hline Binding preference & $\begin{array}{l}\text { Fuc } \alpha 1,6 \text {-linked to proximal GlcNAc of the } \\
\text { trimannosyl core of biantennary N-glycan }\end{array}$ & $\begin{array}{l}\text { Fuc } \alpha 1,3 \text { GlcNAc- in Lewis } \\
\text { of } \mathrm{N} \text { - and O-glycans }\end{array}$ & $\begin{array}{l}\text { Fuc } \alpha 1,2 \text { Gal- } \\
<\text { Fuc }(\alpha 1,3) \text { GlcNAc- or Fuc }(\alpha 1,4) \text { GlcNAc- } \\
\text { in Lewis }{ }^{\mathrm{x}} \text { or Lewis }{ }^{\mathrm{y}} \text { structures of } \mathrm{N} \text { - and O-glycans }\end{array}$ \\
\hline References & $\begin{array}{l}\text { Kornfeld et al. (1981), } \\
\text { Tateno et al. (2009) }\end{array}$ & $\begin{array}{l}\text { Wu et al. (2009), } \\
\text { Yan et al. (1997) }\end{array}$ & $\begin{array}{l}\text { Audette et al. (2000), } \\
\text { Wu et al. (2009) }\end{array}$ \\
\hline
\end{tabular}


to 0.08 depending on the microtiter plate, the lectin used, and the day of the experiment.

\section{Statistical analysis}

The statistical analysis was performed with STATISTICA 12 (StatSoft, Inc., Tulsa, USA). The Kruskal-Wallis test was used for statistical significance. The results are shown as the mean \pm SD and the median with 25 th-75th percentiles. The correlations were estimated according to Spearman. A two-tailed $p$-value of less than 0.05 was considered significant.

\section{Results}

\section{IgG concentration}

The mean value of IgG concentration in milk samples of mothers (Fig. 1A) giving birth to a newborn at term (T group: $18.61 \pm 15.6 \mathrm{mg} / \mathrm{l}$ ), very preterm (VP group: $16.43 \pm 6.1 \mathrm{mg} / \mathrm{l}$ ), and moderate preterm (MP group: $20.06 \pm 13.0 \mathrm{mg} / \mathrm{l}$ ) was at similar level.

The mean value of IgG concentration was high in the early colostrum of the term $(27.85 \pm 23.2 \mathrm{mg} / \mathrm{l})$ and preterm $(41.74 \pm 17.3 \mathrm{mg} / \mathrm{l})$ groups, and then it significantly decreased in the colostrum of term $(14.89 \pm 12.5 \mathrm{mg} / \mathrm{l}, p<0.003)$ and preterm milk $(17.31 \pm 10.1 \mathrm{mg} / \mathrm{l}, p<0.02)$ groups. During further milk maturation IgG concentration was at stable similar level in the transitional as well as mature samples of the term ( $16.84 \pm 11.9$ and $18.06 \pm 7.4 \mathrm{mg} / \mathrm{l}$, respectively) and preterm milk groups $(15.59 \pm 8.4$ and $17.49 \pm 7.8 \mathrm{mg} / \mathrm{l}$, respectively) (Table 3$)$.
The concentration of term and preterm milk IgG showed no correlation with the day of lactation from the 1st/2nd day to the 55th/40th day, respectively (Fig. 2A). However, the concentration of IgG in milk groups showed individual differences and it ranged from the highest observed values of $99.6 \mathrm{mg} / \mathrm{l}$ at the $3 \mathrm{rd}$ day for term milk to the lowest value of about $4 \mathrm{mg} / \mathrm{l}$ at 8 th day of lactation for term milk. The IgG concentration for the term and preterm milk group (mean value $18.61 \pm 15.7$ and $18.30 \pm 10.9 \mathrm{mg} / \mathrm{l}$, respectively) was about 280 times lower than in plasma of mothers at the 2 nd postpartum day $(5.17 \pm 2.4 \mathrm{~g} / \mathrm{l})$.

\section{UEA-reactive $\alpha 1,2$-fucosylated variant of milk IgG}

The mean value of relative UEA reactivity with IgG of term milk samples (Fig. 1B) $(0.53 \pm 0.3 \mathrm{AU})$ was higher than the values for the very $(0.38 \pm 0.3 \mathrm{AU}, p<0.0006)$ and moderate $(0.41 \pm 0.2 \mathrm{AU})$ preterm milk groups.

The relative reactivity of UEA with term and preterm milk IgG showed the highest similar mean values in the early colostrum group $(0.70 \pm 0.3$ and $0.78 \pm 0.7 \mathrm{AU}$, respectively). During progression of lactation, the reactivity decreased in the colostrum group of the term milk $(0.51 \pm 0.3 \mathrm{AU} ; p<0.004)$ and preterm milk $(0.49 \pm 0.2 \mathrm{AU})$. In subsequent stages of milk maturation, the reactivity remained almost unchanged in the term and preterm groups of transitional $(0.46 \pm 0.2$ and $0.40 \pm 0.2 \mathrm{AU}$, respectively) and mature $(0.44 \pm 0.2$ and $0.37 \pm 0.3 \mathrm{AU}$, respectively) milk groups. On the other hand, only the UEA reactivity with IgG of the term mature milk group $(0.44 \pm 0.2 \mathrm{AU})$ showed a significant higher $(p<0.02)$ mean value when compared with the reactivity for the mature preterm milk group $(0.37 \pm 0.3 \mathrm{AU})$ (Table 3$)$.
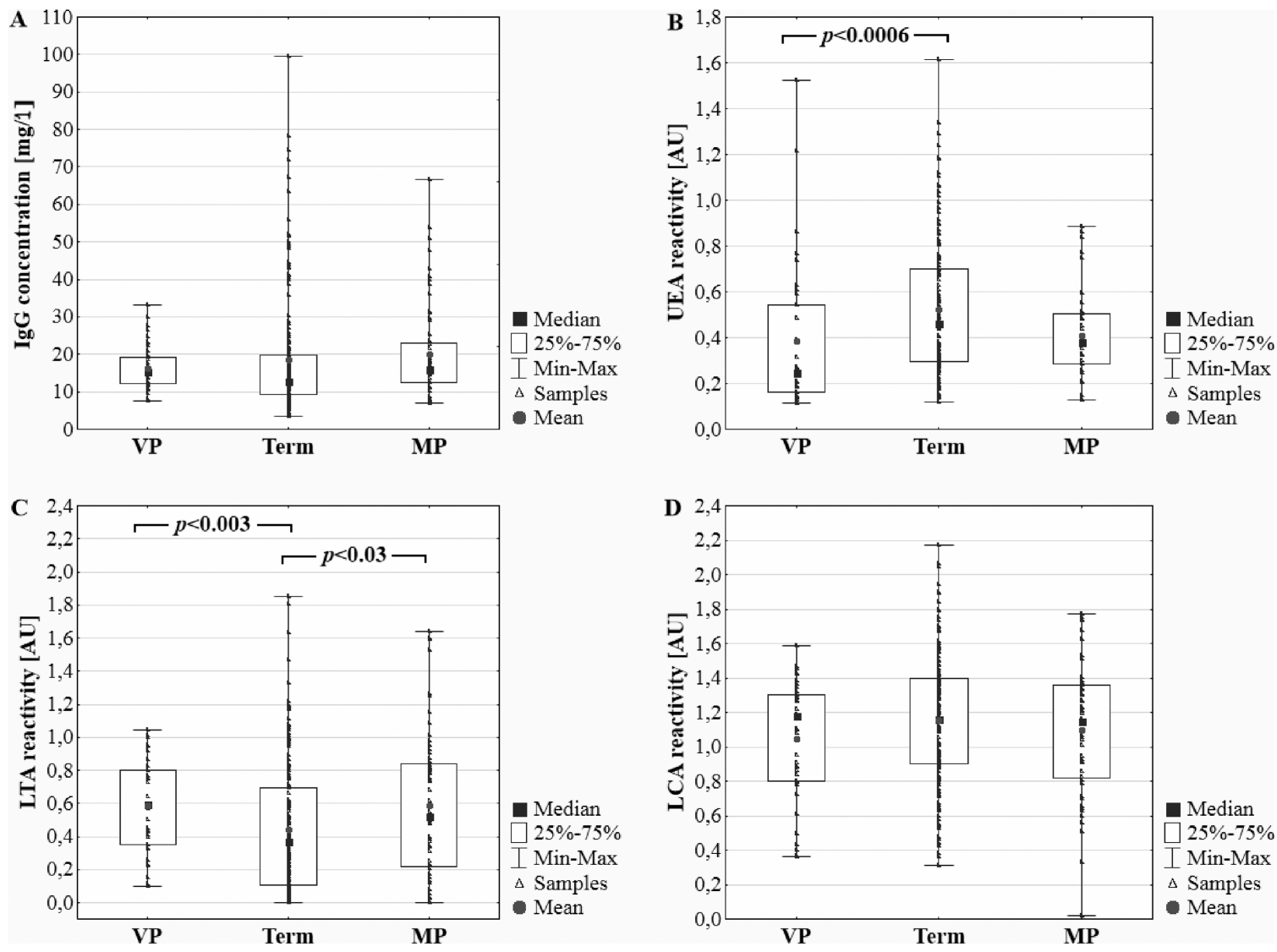

Fig. 1. IgG concentration (A) and relative amount (AU) of Ulex europaeus, UEA; (B) Tetragonolobus purpureus, LTA; (C) and Lens culinaris, LCA; (D) reactive IgG glycovariants in skim term and preterm milk. The IgG concentration and lectin reactivity with skim milk IgG were determined as described in materials and methods. VP: very preterm, and MP: moderate preterm milk; AU: absorbance units. 
Table 3

IgG concentration and relative amounts of fucosyl-IgG glycoforms during lactation in milk from mothers giving birth to term and preterm infants.

\begin{tabular}{|c|c|c|c|c|c|}
\hline \multirow[t]{4}{*}{ No. } & \multirow[t]{4}{*}{ Groups and number of samples } & \multirow[t]{4}{*}{$\operatorname{IgG}[\mathrm{mg} / \mathrm{l}]$} & \multicolumn{3}{|c|}{ IgG reactivity $[\mathrm{AU}]$ with lectins } \\
\hline & & & UEA & LTA & LCA \\
\hline & & & \multicolumn{3}{|c|}{ specific to a fucose linked by the glycosidic linkages } \\
\hline & & & $\alpha 1,2^{\mathrm{a}}$ & $\alpha 1,3$ & $\alpha 1,6$ \\
\hline \multirow[t]{2}{*}{$\begin{array}{l}\text { 1. Early colostrum } \\
\text { days } 1-3\end{array}$} & Term $(n=40)$ & $\begin{array}{l}27.85 \pm 23.216 .81 \\
(9.46-46.24)\end{array}$ & $\begin{array}{l}0.70 \pm 0.30 .69 \\
(0.45-0.98) n^{\mathrm{a}}=32\end{array}$ & $\begin{array}{l}0.28 \pm 0.30 .15 \\
(0.06-0.40)\end{array}$ & $\begin{array}{l}1.18 \pm 0.41 .04 \\
(0.89-1.53)\end{array}$ \\
\hline & Preterm $(n=6)$ & $\begin{array}{l}41.74 \pm 17.344 .36 \\
(27.20-53.96)\end{array}$ & $\begin{array}{l}0.78 \pm 0.70 .41 \\
(0.21-1.52)\end{array}$ & $\begin{array}{l}0.21 \pm 0.30 .06 \\
(0.004-0.21)\end{array}$ & $\begin{array}{l}1.07 \pm 0.30 .92 \\
(0.83-1.40)\end{array}$ \\
\hline \multirow[t]{2}{*}{$\begin{array}{l}\text { 2. Colostrum } \\
\text { days } 4-7\end{array}$} & Term $(n=75)$ & $\begin{array}{l}14.89 \pm 12.510 .69 \\
(7.71-16.92) \\
p<0.003^{1 \mathrm{~T}}\end{array}$ & $\begin{array}{l}0.51 \pm 0.30 .44 \\
(0.29-0.68) n^{\mathrm{a}}=64 \\
p<0.004^{1 \mathrm{~T}}\end{array}$ & $\begin{array}{l}0.50 \pm 0.50 .39 \\
(0.11-0.83) \\
p<0.02^{1 \mathrm{~T}}\end{array}$ & $\begin{array}{l}1.24 \pm 0.41 .25 \\
(0.97-1.41)\end{array}$ \\
\hline & Preterm $(n=15)$ & $\begin{array}{l}17.31 \pm 10.113 .87 \\
(8.47-23.46) \\
p<0.02^{1 \mathrm{P}}\end{array}$ & $\begin{array}{l}0.49 \pm 0.20 .54 \\
(0.29-0.59) n^{\mathrm{a}}=13\end{array}$ & $\begin{array}{l}0.54 \pm 0.40 .45 \\
(0.16-0.90)\end{array}$ & $\begin{array}{l}1.12 \pm 0.51 .10 \\
(0.79-1.74)\end{array}$ \\
\hline \multirow[t]{2}{*}{$\begin{array}{l}\text { 3. Transitional milk } \\
\text { days } 8-14\end{array}$} & Term $(n=43)$ & $\begin{array}{l}16.84 \pm 11.912 .89 \\
(9.87-18.68)\end{array}$ & $\begin{array}{l}0.46 \pm 0.20 .37 \\
(0.29-0.54) n^{\mathrm{a}}=35\end{array}$ & $\begin{array}{l}0.42 \pm 0.30 .40 \\
(0.10-0.62)\end{array}$ & $\begin{array}{l}1.07 \pm 0.31 .12 \\
(0.78-1.34) \\
p<0.04^{2 \mathrm{~T}}\end{array}$ \\
\hline & Preterm $(n=30)$ & $\begin{array}{l}15.59 \pm 8.412 .89 \\
(10.26-17.90)\end{array}$ & $\begin{array}{l}0.40 \pm 0.20 .38 \\
(0.28-0.49) n^{\mathrm{a}}=25\end{array}$ & $\begin{array}{l}0.71 \pm 0.40 .73 \\
(0.39-0.93) \\
p<0.002^{3 \mathrm{~T}}\end{array}$ & $\begin{array}{l}1.07 \pm 0.41 .10 \\
(0.79-1.37)\end{array}$ \\
\hline \multirow[t]{2}{*}{$\begin{array}{l}\text { 4. Mature milk } \\
\text { days } 15-55\end{array}$} & Term $(n=28)$ & $\begin{array}{l}18.06 \pm 7.417 .67 \\
(11.89-21.42)\end{array}$ & $\begin{array}{l}0.44 \pm 0.20 .35 \\
(0.28-0.60) n^{\mathrm{a}}=24\end{array}$ & $\begin{array}{l}0.57 \pm 0.30 .58 \\
(0.33-0.76)\end{array}$ & $\begin{array}{l}1.05 \pm 0.41 .08 \\
(0.81-1.40)\end{array}$ \\
\hline & Preterm $(n=55)$ & $\begin{array}{l}17.49 \pm 7.816 .77 \\
(12.42-19.70)\end{array}$ & $\begin{array}{l}0.37 \pm 0.30 .25 \\
(0.16-0.39) n^{\mathrm{a}}=33 \\
p<0.02^{4 \mathrm{~T}}\end{array}$ & $\begin{array}{l}0.54 \pm 0.30 .55 \\
(0.26-0.79)\end{array}$ & $\begin{array}{l}1.06 \pm 0.31 .18 \\
(0.80-1.30)\end{array}$ \\
\hline 5. Lactating mother's plasma & $(n=64)$ & $\begin{array}{l}5.17 \pm 2.4 \mathrm{~g} / \mathrm{l} 4.46 \\
(3.41-7.47)\end{array}$ & $0.0 \pm 0.0$ & $0.0 \pm 0.0$ & $\begin{array}{l}0.1 \pm 0.010 .1 \\
(0.07-0.14)\end{array}$ \\
\hline
\end{tabular}

Note: $n$ - number of samples; values are given as the mean \pm SD and median and 25th-75th percentile in parentheses. The Kruskal-Wallis test was used for statistical calculations, and $p$-value lower than 0.05 was regarded as significant. Significantly different from the milk sample group of: ${ }^{1 \mathrm{~T}}$ term early colostrum (1-3 days), ${ }^{2 \mathrm{~T}}$ term colostrum (4-7 days), ${ }^{3 \mathrm{~T}}$ term transitional milk, ${ }^{4 \mathrm{~T}}$ term mature milk, ${ }^{1 \mathrm{P}}$ preterm early colostrum (2-3 days).

The reactivity of $200 \mathrm{ng}$ of milk or lactating mother's plasma IgG with Lens culinaris agglutinin (LCA) (specific to $\alpha 1,6$-linked fucose), Tetragonolobus purpureus agglutinin (LTA) (specific to $\alpha 1$,3-linked fucose), and Ulex europaeus agglutinin (UEA) (specific to $\alpha 1,2$-linked fucose) is expressed as the absolute value of absorbance units (AU) at 405 nm based on the lectin-IgG-ELISA as described in materials and methods.

${ }^{a}$ Milk samples which did not react with UEA (derived from non-secretor mothers) were excluded from the statistical analysis.

The expression of UEA-reactive glycotopes on IgG showed a weak negative correlation with lactation from 1st/2nd to 55th/ 40th days in the term $(r=-0.28 ; p<0.05)$ and preterm $(r=-0.31$; $p<0.05$ ) groups (Fig. 2B).

\section{LTA-reactive $\alpha 1,3$-fucosylated variant of milk $\operatorname{IgG}$}

The mean value of LTA relative reactivity with $\operatorname{IgG}$ of milk (Fig. 1C) in the very (VP, $0.59 \pm 0.3 \mathrm{AU}, p<0.003$ ) and moderate (MP, $0.58 \pm 0.4 \mathrm{AU}, p<0.03$ ) preterm milk groups was higher than in the term milk group $(0.45 \pm 0.4 \mathrm{AU})$.

The relative reactivity of LTA with milk IgG was the lowest at the beginning of lactation in the early colostrum samples of term $(0.28 \pm 0.3 \mathrm{AU})$ and preterm $(0.21 \pm 0.3 \mathrm{AU})$ groups and it increased in the groups of colostrum of the term $(0.50 \pm 0.5 \mathrm{AU}, p<0.02)$ and preterm milk $(0.54 \pm 0.4 \mathrm{AU})$. During further milk maturation stages, the LTA reactivity with IgG of the term and preterm milk samples of transitional $(0.42 \pm 0.3$ and $0.71 \pm 0.4 \mathrm{AU}$, respectively) and mature milk $(0.57 \pm 0.3$ and $0.54 \pm 0.3 \mathrm{AU}$, respectively) did not change significantly compared with the values for the colostrum groups (Table 3 ). However, the high reactivity of LTA with milk IgG of transitional milk samples of the preterm group $(0.71 \pm 0.4 \mathrm{AU})$ was found to be significantly higher $(p<0.002)$ than in the corresponding term milk group $(0.42 \pm 0.3 \mathrm{AU})$.

The expression of LTA-reactive glycotopes of IgG showed a weak positive correlation $(r=0.27 ; p<0.05)$ with a lactation for the term milk group, whereas that of the preterm milk group did not (Fig. 2C).

\section{LCA-reactive $\alpha 1,6$-fucosylated variant of milk $\operatorname{Ig} G$}

The relative reactivity of LCA with IgG of milk (Fig. 1D) of mothers giving a newborn at term (T group: $1.16 \pm 0.4 \mathrm{AU}$ ) and for those of the VP and MP preterm milk groups were found to be nearly at the same level ( $1.05 \pm 0.3$ and $1.10 \pm 0.4 \mathrm{AU}$, respectively).

In the early colostrum group of term and preterm milk samples the relative reactivity of LCA with $\operatorname{IgG}$ was high $(1.18 \pm 0.4$ and $1.07 \pm 0.3 \mathrm{AU}$, respectively) and remained almost at the same level in the colostrum samples $(1.24 \pm 0.4$ and $1.12 \pm 0.5 \mathrm{AU}$, respectively). Following the period of 1 st -7 th days of lactation the reactivity of LCA with IgG decreased in transitional term milk group $(1.07 \pm 0.3 \mathrm{AU}, p<0.04)$, whereas for the preterm group was almost unchanged $(1.07 \pm 0.4 \mathrm{AU})$, and remained at the same level in the mature milk group of the term and preterm samples $(1.05 \pm 0.4$ and $1.06 \pm 0.3 \mathrm{AU}$, respectively) (Table 3, Fig. 2D).

In contrast, $200 \mathrm{ng}$ of lactating mothers' plasma IgG was very weakly recognized by LCA $(0.1 \pm 0.01 \mathrm{AU})$ but not by UEA and LTA.

Lectin-reactive fucosylated IgG variants in preterm milk in relation to infection of mothers

The mean values of the relative reactivity of UEA and LTA with IgG of preterm milk of mothers having infections (Fig. 3A, B) were significantly lower $(0.38 \pm 0.3 \mathrm{AU}, p<0.009)$ and higher $(0.69 \pm 0.4$ AU, $p<0.002)$, respectively than those values found for the preterm milk group without infection $(0.48 \pm 0.3$ and $0.47 \pm 0.4$ $\mathrm{AU}$, respectively).

In contrast, the mean values of the LCA relative reactivity with IgG of preterm milk of mothers who had and without infection were similar ( $1.10 \pm 0.3$ and $1.04 \pm 0.4 \mathrm{AU}$, respectively) (Fig. 3C).

\section{Discussion}

In spite of the fact that the binding specificity of lectins is not absolute and their using did not allow to determine the "true" glycan structures, they are especially helpful to observe the 


\section{Group of "term milk"}

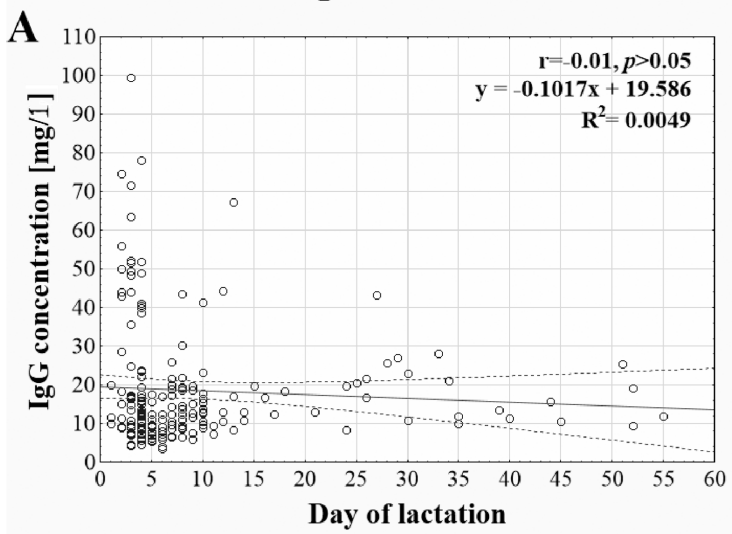

B

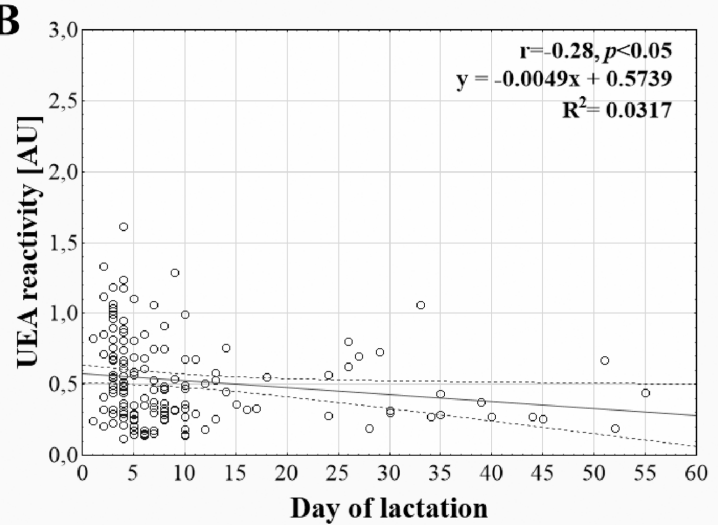

C

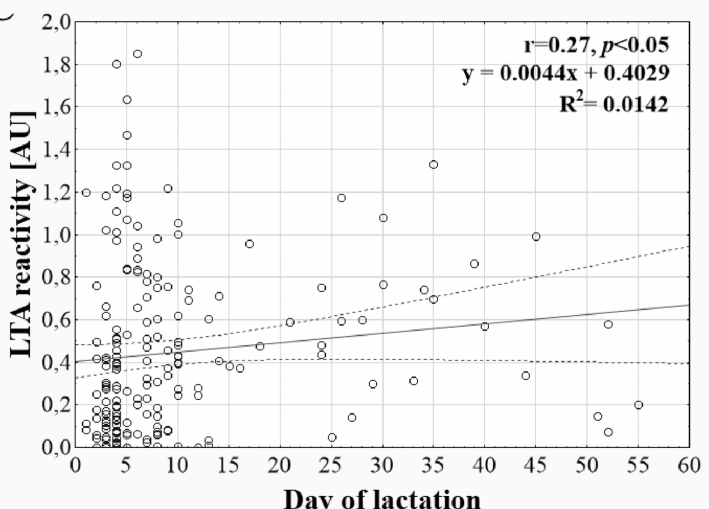

D

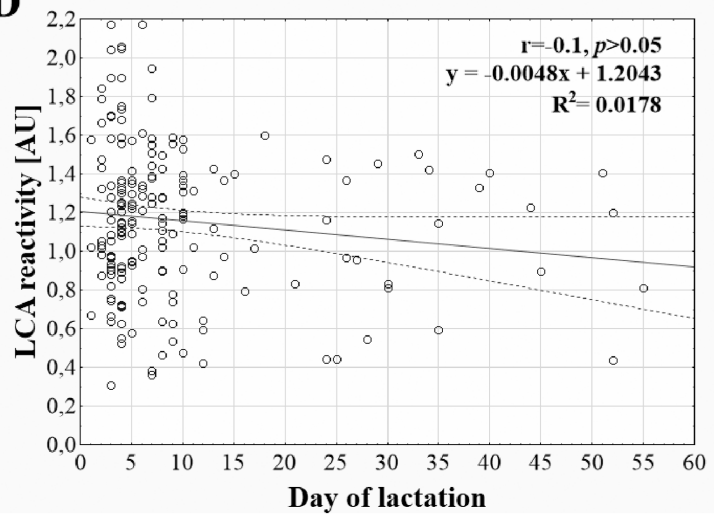

Group of "preterm milk"
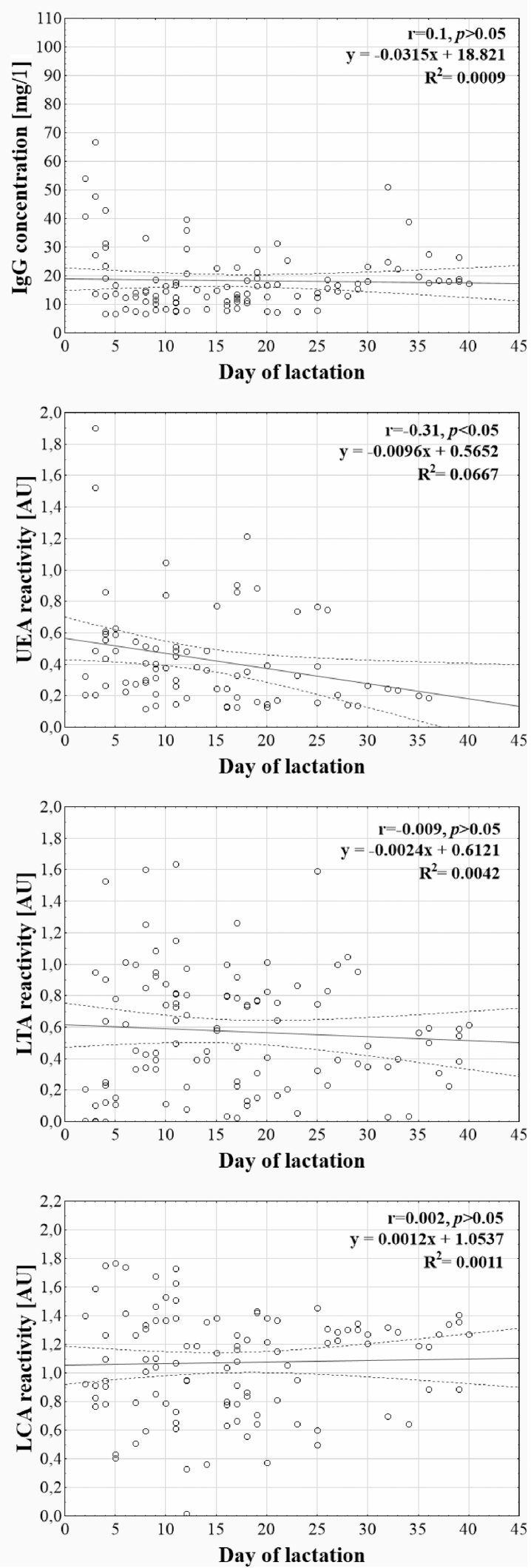

Fig. 2. IgG concentration (A) and reactivity of fucose-specific lectins UEA (B), LTA(C) and LCA (D) with milk IgG over lactation of mothers giving birth to term and preterm newborns. A solid line indicates linear regression, and 95\% confidence intervals are shown by dotted lines. Correlation coefficient $(r)$ was calculated with lactation days according to Spearman and $p$-value lower than 0.05 was regarded as significant. $R^{2}$ value is the square of the correlation coefficient of the linear regression between the day of lactation and lectin reactivity $[\mathrm{AU}]$ or $\operatorname{IgG}$ concentration $(\mathrm{mg} / \mathrm{l})$. For details see under Fig. 1. 

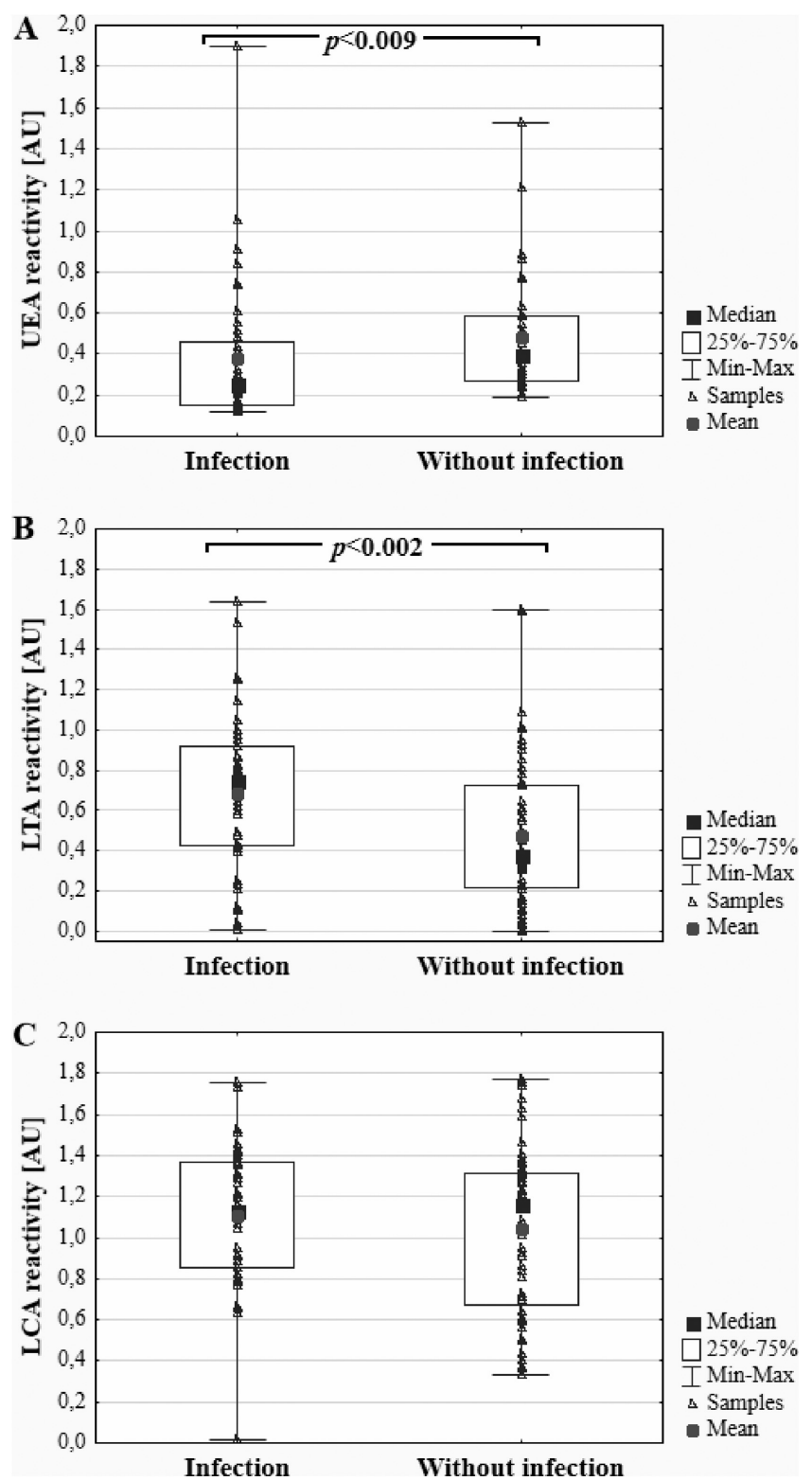

Fig. 3. Relative amount (AU) of UEA (A), LTA (B) and LCA (C) reactive IgG glycovariant in skim preterm milk of mothers with and without infection. For details see under Fig. 1.

changes of terminal sugar expressions on glycoconjugates which in vivo might be ligand for endogenous selectins and/or bacterial lectins. Our results showed that during lactation human milk IgG was highly reactive, in contrast to poorly reactive maternal plasma IgG, with UEA, LTA, and LCA, lectins specific to fucose linked to oligosaccharide part by $\alpha 1,2-, \alpha 1,3-$, and $\alpha 1,6$-linkages, respectively (Table 3 ). The fucosylation pattern of IgG of the very preterm and preterm milk samples differed from those of the term milk samples by the lower $\alpha 1,2-$, higher $\alpha 1,3-$, and nearly stable $\alpha 1,6$ - linked fucose expressions (Fig. 1). Moreover, the lower amounts of $\alpha 1,2$ - and higher of $\alpha 1,3$-lectin-dependent milk IgG fucosylated glycovariants were found to be associated with infection of lactating mothers (Fig. 3).

The composition of human milk after preterm delivery is reported to be altered compared with full-term pregnancy (Mehta and Petrova, 2011; Molinari et al., 2012), and contains significantly higher concentrations of some immune proteins than term milk (Broadhurst et al., 2015; Trend et al., 2016). The highest concentration of IgG in the early colostrum (Table 3 ) seem to be a result of milk compaction at the beginning of lactation and in the case of preterm milk might be associated with abnormalities during the perinatal period (Table 1 ). In spite of above and in contrast to the total protein, lactoferrin, and S-IgA levels during lactation (Froehlich et al., 2010; Lönnerdal, 2013; Trend et al., 2016), the concentration of $\operatorname{IgG}$ was at relatively stable level of $18 \mathrm{mg} / \mathrm{l}$ in term and preterm milk. That value is consistent with that of about $20 \mathrm{mg} / \mathrm{l}$ given by Broadhurst et al. (2015) and lower than established by Koenig et al. (2005). Observed a large variation of IgG concentration among lactating mothers seems to be associated with the inherent physiological differences between individual mothers, ethnicity, diet, age, lifestyle choices, and the presence of subclinical disease (Broadhurst et al., 2015; Yuen et al., 2012).

Lectin-based analysis reveals the presence of $\alpha 1,6-, \alpha 1,2$, and $\alpha 1,3$ - fucosylated IgG glycovariants in milk and their absence or negligible amount on lactating mothers' plasma IgG (Table 3). Such significant differences may result from, at least partially, local milk IgG synthesis in mammary gland hormonally regulated (Hurley and Theil, 2011). However, the strong reaction of milk IgG with LCA, in contrast to very weak reaction of plasma IgG, may reflect some structural differences and altered accessibility of $\alpha 1,6$-linked fucose residue on milk and plasma IgG for the reaction with lectin. Shade and Anthony (2013) reported that oligosaccharides of Fc fragment of plasma IgG were concealed in the cavity between two C $\gamma 2$ domains and thus, in our opinion, core $\alpha 1$,6-linked fucose of plasma IgG was not recognized by LCA in lectin-ELISA. Moreover, the milk IgG may have some fucosylated glycans attached to Fab fragment, which were not found on plasma IgG, but appeared for example at the Fab portion during pregnancy (Bondt et al., 2014) and myeloma IgG (Kinoshita et al., 1991).

In contrast to the relatively stable expression of $\alpha 1,6$ - fucosylated glycotope on term and preterm milk IgG during milk maturation, the pattern of changes in the expression of $\alpha 1,2$ - and $\alpha 1,3$-fucosylated glycotopes on IgG was variable for UEA- and LTA-reactive glycovariants. The highest expression of glycotope $\alpha 1,2$-fucosylated, observed several hours after delivery in term and preterm early colostrum IgG (Table 3 ), although lower in the very and moderate preterm milk samples than in term milk group (Fig. 1B), decreased with milk maturation (Table 3, Fig. 2B). In contrast, the relative amount of LTA-reactive milk IgG glycovariant containing an $\alpha 1,3$-fucose, a part of inflammationrelated Lewis ${ }^{\mathrm{x}}$ antigen, was evidently higher in milk samples derived from very preterm and moderate preterm groups than in samples of the term group (Fig. 1C). However, for term and preterm group its expression was the lowest at the beginning of lactation, and it reached the highest level in the preterm transitional milk group, (Table 3 ) formed in $50 \%$ of mothers who had an infection. In our opinion, the expression of LTA-reactive $\alpha 1,3$-fucosylated Lewis ${ }^{\mathrm{x}}$ antigen was mainly associated with infection, in women who delivered preterm (Fig. 3B) and to a lesser degree with delivery-associated inflammatory phase, as well as postpartum hormonal imbalance (Groër et al., 2005). The high expression of $\alpha 1,3$-fucosylated glycotope on preterm milk IgG of the infection group correlated with the decrease of $\alpha 1,2$-fucosylated glycotope (Fig. 3A, B). That fact might be associated with the synthesis of sialyl-Lewis ${ }^{\mathrm{x}}$ antigen, whose constrains the attachment of fucose through $\alpha 1,2$-linkage to outer antenna of $\mathrm{N}$-glycans (Bieberich, 2014) and occurrence was related to inflammation (Van Dijk et al., 1998).

The described fucosylation pattern for milk IgG characteristic for term and preterm milk maturation overlapped in part with the trends for glycoconjugates (Nwosu et al., 2012), fucosylated glycovariants of fibronectin (Orczyk-Pawiłowicz et al., 2015), $\alpha$-1-acid glycoprotein (Orczyk-Pawiłowicz et al., 2014), and that 
for HMOs (De Leoz et al., 2012). The differences in fucosylation of term and preterm milk IgG during lactation might be related to immaturity of mammary gland of preterm delivered mothers and with interindividual variability. According to De Leoz et al. (2012) the lower and more variable fucosylation of HMOs of preterm milk than that of term milk is associated with dysregulation of breast cells (insufficient levels of hormones and not fully completed remodelling of mammary gland tissue) during preterm lactation. IgG acts not only as specific antibody, but due to the fucose exposed on surface is able to participate in reactions of biological recognition (Arnold et al., 2007; Bode, 2012; Newburg, 1996). The presence of the LCA-reactive $\alpha 1,6$-fucosylated IgG glycovariant in human milk is believed to have importance in immunoprotection of the incompletely developed immune system of newborns, namely differentiation of the intestinal epithelium of newborns and cell-cell signalling and adhesion (Becker and Lowe, 2003; Jakaitis and Denning, 2014). The high $\alpha 1,2-$ and $\alpha 1,6-$ fucosylation of some milk glycoproteins is reported to be associated with anti-pathogenic function of fucosylated glycotopes (Kątnik-Prastowska and Orczyk-Pawiłowicz, 2011; Orczyk-Pawiłowicz et al., 2014; Royle et al., 2003) and might participate as a decoy for fucose-dependent pathogens via lectin-carbohydrate interactions and prevent adhesion to host epithelial cells. The maturation of immune and gastrointestinal systems of newborns starts during fetal development and is modulated by amniotic immunological components. Provision of maternal milk to newborns is a continuation of the immunoprotective and immunomodulatory effect of amniotic fluid (Goldblum and Hilton, 1999; Wagner, 2002).

\section{Conclusion}

Biologically active highly fucosylated milk IgG seems to constitute bifunctional molecules which are able to act as specific antibodies and moreover, thanks to their exposed monosaccharide residues, as inhibitors of fucose-dependent bacteria tissue colonization playing thus a role in innate immunity. Therefore, breastfeeding is important not only as a natural immunological "substitution therapy" for deficient secretory immunity of newborns, but also because of immune-modulating function of milk glycans, which provides some kind of innate protection, exerts an important impact on the developing immune system of the newborn. The glycostatus analysis of biologically active milk molecules may be helpful to control the immunological quality of milk for milk banking.

\section{Conflict of interests}

The authors declare that they have no conflict of interests.

\section{Acknowledgement}

This work was supported by the Medical Faculty (No Pbmn 137), Wrocław Medical University, Poland.

\section{References}

AAP, 2012. policy statement breastfeeding and the use of human milk. Pediatrics 129, e827-e841.

Arnold, J.N., Royle, L., Dwek, R.A., Rudd, P.M., Sim, R.B., 2005. Human immunoglobulin glycosylation and the lectin pathway of complement activation. Adv. Exp. Med. Biol. 564, 27-43.

Arnold, J.N., Wormald, M.R., Sim, R.B., Rudd, P.M., Dwek, R.A., 2007. The impact of glycosylation on the biological function and structure of human immunoglobulins. Annu. Rev. Immunol. 25, 21-50.

Audette, G.F., Vandonselaar, M., Delbaere, L.T., 2000. The 2.2 A resolution structure of the $\mathrm{O}(\mathrm{H})$ blood-group-specific lectin I from Ulex europaeus. J. Mol. Biol. 304, 423-433.
Becker, D.J., Lowe, J.B., 2003. Fucose: biosynthesis and biologic function in mammals. Glycobiology 13, 41R-53R.

Bieberich, E., 2014. Synthesis, processing, and function of $\mathrm{N}$-glycans in N-glycoproteins. Adv. Neurobiol. 9, 47-70.

Bode, L., 2012. Human milk oligosaccharides: every baby needs a sugar mama. Glycobiology 22, 1147-1162.

Bondt, A., Rombouts, Y., Selman, M.H., Hensbergen, P.J., Reiding, K.R., Hazes, J.M., et al., 2014. Immunoglobulin G (IgG) Fab glycosylation analysis using a new mass spectrometric high-throughput profiling method reveals pregnancy-associated changes. Mol. Cell Proteomics 13, 3029-3039.

Broadhurst, M., Beddis, K., Black, J., Henderson, H., Nair, A., Wheeler, T., 2015. Effect of gestation length on the levels of five innate defence proteins in human milk. Early Hum. Dev. 91, 7-11.

Chirico, G., Marzollo, R., Cortinovis, S., Fonte, C., Gasparoni, A., 2008. Antiinfective properties of human milk. J. Nutr. 138, 1801S-1806S.

De Leoz, M.L., Gaerlan, S.C., Strum, J.S., Dimapasoc, L.M., Mirmiran, M., Tancredi, D.J. et al., 2012. Lacto-N-tetraose, fucosylation, and secretor status are highly variable in human milk oligosaccharides from women delivering preterm. J. Proteome Res. 11, 4662-4672.

França, E.L., Nicomedes, T.R., Calderon, I.M., Honorio-França, A.C., 2010. Timedependent alterations of soluble and cellular components in human milk. Biol. Rhythm. Res. 5, 333-347.

França, E.L., Calderon, Ide M., Vieira, E.L., Morceli, Honorio-França, A.C., 2012. Transfer of maternal immunity to newborns of diabetic mothers. Clin. Dev. Immunol. 2012.

Freedman, D.J., Tacket, C.O., Delehanty, A., Maneval, D.R., Nataro, J., Crabb, J.H., 1998 Milk immunoglobulin with specific activity against purified colonization factor antigens can protect against oral challenge with enterotoxigenic Escherichia coli. J. Infect. Dis. 177, 662-667.

Froehlich, J.W., Dodds, E.D., Barboza, M., Mcjimpsey, E.L., Seipert, R.R., Francis, J., et al., 2010. Glycoprotein expression in human milk during lactation. J. Agric. Food Chem. 58, 6440-6448.

Goldblum, R.M., Hilton, S., 1999. Amniotic fluid and the fetal mucosal immune system. In: Ogra, P.L., Mestecky, J., Lamm, M.E. (Eds.), Mucosal Immunology. Academic Press, London, pp. 2251-2268.

Gornik, O., Pavić, T., Lauc, G., 2012. Alternative glycosylation modulates function of IgG and other proteins-implications on evolution and disease. Biochim. Biophys. Acta 182, 1318-1326.

Groër, M., Davis, M., Casey, K., Short, B., Smith, K., Groër, S., 2005. Neuroendocrine and immune relationships in postpartum fatigue. MCN Am. J. Matern. Child Nurs. 30, 133-138.

Hurley, W.L., Theil, P.K., 2011. Perspectives on immunoglobulins in colostrum and milk. Nutrients 3, 442-474.

Jakaitis, B.M., Denning, P.W., 2014. Human breast milk and the gastrointestinal innate immune system. Clin. Perinatol. 41, 423-435.

Katnik, I., Jadach, J., Krotkiewski, H., Gerber, J., 1994. Investigating the glycosylation of normal and ovarian cancer hepatoglobins using digoxigenin-labelled lectins. Glycosyl. Dis. 1, 97-104.

Kątnik-Prastowska, I., Orczyk-Pawiłowicz, M., 2011. Expression and potential biological role of $\alpha(1,2)$ fucosylated glycotopes on amniotic and seminal fibronectins. Biochem. Soc. Trans. 39, 355-359.

Kaneko, Y., Nimmerjahn, F., Ravetch, J.V., 2006. Anti-inflammatory activity of immunoglobulin G resulting from Fc sialylation. Science 313, 670-673.

Kinoshita, N., Ohno, M., Nishiura, T., Fujii, S., Nishikawa, A., Kawakami, Y., et al., 1991. Glycosylation at the Fab portion of myeloma immunoglobulin $\mathrm{G}$ and increased fucosylated biantennary sugar chains: structural analysis by high-performance liquid chromatography and antibody-lectin enzyme immunoassay using Lens culinaris agglutinin. Cancer Res. 51, 5888-5892.

Koenig, A., de Albuquerque Diniz, E.M., Barbosa, S.F., Vaz, F.A., 2005. Immunologic factors in human milk: the effects of gestational age and pasteurization. J. Hum. Lact. 21, 439-443.

Kornfeld, K., Reitman, M.L., Kornfeld, R., 1981. The carbohydrate-binding specificity of pea and lentil lectins: fucose is an important determinant. J. Biol. Chem. 256 6633-6640.

Lönnerdal, B., 2013. Bioactive proteins in breast milk. J. Paediatr. Child Health 1, $1-7$.

Mehta, R., Petrova, A., 2011. Biologically active breast milk proteins in association with very preterm delivery and stage of lactation. J. Perinatol. 31, 58-62.

Molinari, C.E., Casadio, Y.S., Hartmann, B.T., Livk, A., Bringans, S., Arthur, P.G. Hartmann, P.E., 2012. Proteome mapping of human skim milk proteins in term and preterm milk. J. Proteome Res. 11, 1696-1714.

Newburg, D.S., 1996. Oligosaccharides and glycoconjugates in human milk: their role in host defence. J. Mammary Gland Biol. Neoplasia 1, 271-283.

Nimmerjahn, F., Ravetch, J.V., 2007. Fc-receptors as regulators of immunity. Adv. Immunol. 96, 179-204.

Nwosu, C.C., Aldredge, D.L., Lee, H., Lerno, L.A., Zivkovic, A.M., German, J.B., Lebrilla, C.B., 2012. Comparison of the human and bovine milk N-glycome via highperformance microfluidic chip liquid chromatography and tandem mass spectrometry. J. Proteome Res. 11, 2912-2924.

Orczyk-Pawiłowicz, M., Kątnik-Prastowska, I., 2011. Terminal monosaccharide expression on amniotic glycoproteins as biomarkers of fetus maturity. Biochem. Soc. Trans. 39, 344-348.

Orczyk-Pawiłowicz, M., Augustyniak, D., Hirnle, L., Kątnik-Prastowska, I., 2012. Degree of sialylation and fucosylation of plasma and amniotic immunoglobulin $\mathrm{G}$ changes progressively during normal pregnancy. Prenat. Diagn. 32, 432-439. 
Orczyk-Pawiłowicz, M., Hirnle, L., Berghausen-Mazur, M., Kątnik-Prastowska, I.M., 2014. Lactation stage-related expression of sialylated and fucosylated glycotopes of human milk $\alpha$-1-acid glycoprotein. Breastfeed. Med. 9, 313-319.

Orczyk-Pawiłowicz, M., Hirnle, L., Berghausen-Mazur, M., Kątnik-Prastowska, I., 2015. Terminal glycotope expression on milk fibronectin differs from plasma fibronectin and changes over lactation. Clin. Biochem. 48, 167-173.

Plomp, R., Dekkers, G., Rombouts, Y., Visser, R., Koeleman, C.A., Kammeijer, G.S., et al., 2015. Hinge-region O-glycosylation of human immunoglobulin G3 (IgG3). Mol. Cell Proteomics 14, 1373-1384.

Royle, L., Roos, A., Harvey, D.J., Wormald, M.R., van Gijlswijk-Janssen, D., Redwan, E.R.M., et al., 2003. Secretory IgA N- and O-glycans provide a link between the innate and adaptive immune systems. J. Biol. Chem. 278, 20140-20153.

Shade, K.T.C., Anthony, R.M., 2013. Antibody glycosylation and inflammation. Antibodies 2, 392-414.

Tateno, H., Nakamura-Tsuruta, S., Hirabayashi, J., 2009. Comparative analysis of core-fucose-binding lectins from Lens culinaris and Pisum sativum using frontal affinity chromatography. Glycobiology 19, 527-536.

Thieker, D.F., Hadden, J.A., Schulten, K., Woods, R.J., 2016. 3D Implementation of the symbol nomenclature for graphical representation of glycans. Glycobiology 26 , 786-787.

Trend, S., Strunk, T., Lloyd, M.L., Kok, C.H., Metcalfe, J., Geddes, D.T., et al., 2016. Levels of innate immune factors in preterm and term mothers' breast milk during the 1st month postpartum. Br. J. Nutr. 115, 1178-1193.

Van Dijk, W., Brinkman-Van der Linden, E.C., Havenaar, E.C., 1998. Occurrence and possible function of inflammation-induced expression of sialyl Lewis-x on acute-phase proteins. Adv. Exp. Med. Biol. 435, 145-150.
Vidarsson, G., Dekkers, G., Rispens, T., 2014. IgG subclasses and allotypes: from structure to effector functions. Front. Immunol. 5, 520.

WHO Laws to protect breastfeeding inadequate in most countries, 2016. [online] [cit. 2017-05-05]. Available from: http://www.who.int/mediacentre/news/ releases/2016/breastfeeding/en/.

WHO Preterm births 2016. [online] [cit. 2017-05-05]. Available from: http://www. who.int/mediacentre/factsheets/fs363/en/.

Wagner, C.L., 2002. Amniotic fluid and human milk: a continuum of effect? J. Pediatr. Gastroenterol. Nutr. 34, 513-514.

Wilson, C.B., Ogra, P.L., 2011. Human milk. In: Remington, J.S., Klein, J.O., Wilson, C.B., Baker, C.J. (Eds.), Infectious Diseases of the Fetus and Newborn Infant. Elsevier, Amsterdam, pp. 1231-1260.

Wu, A.M., Lisowska, E., Duk, M., Yang, Z., 2009. Lectins as tools in glycoconjugate research. Glycoconj. J. 26, 899-913.

Yan, L., Wilkins, P.P., Alvarez-Manilla, G., Do, S.I., Smith, D.F., Cummings, R.D., 1997. Immobilized Lotus tetragonolobus agglutinin binds oligosaccharides containing the Lex determinant. Glycoconj. J. 14, 45-55.

Yuen, J.W., Loke, A.Y., Gohel, M.D., 2012. Nutritional and immunological characteristics of fresh and refrigerated stored human milk in Hong Kong: a pilot study. Clin. Chim. Acta 413, 1549-1554.

Zauner, G., Selman, M.H., Bondt, A., Rombouts, Y., Blank, D., Deelder, A.M., Wuhrer, M., 2013. Glycoproteomic analysis of antibodies. Mol. Cell Proteomics 12, 856865.

Zhang, Q., Cundiff, J.K., Maria, S.D., McMahon, R.J., Woo, J.G., Davidson, B.S., Morrow, A.L., 2013. Quantitative analysis of the human milk whey proteome reveals developing milk and mammary-gland functions across the first year of lactation. Proteomes 1, 128-158. 